\title{
Consecuencias jurisdiccionales asociadas a la multiplicación de tribunales internacionales: ¿¿en qué consisten los potenciales riesgos?
}

Fecha de recepción: 31 de agosto de 2014

Fecha de aceptación: 18 de septiembre de 2015

Doi: dx.doi.org/10.12804/acdi9.1.2016.01

\section{Carlos Bellei Tagle*}

Resumen: El sistema de solución de controversias es un aspecto esencial para otorgar eficacia al derecho internacional. Durante los últimos años, ha experimentado varias transformaciones, la más significativa de todas, la multiplicación de cortes y tribunales internacionales. Este trabajo explora los distintos efectos que dicho proceso ha generado, centrándose en aquellos considerados como negativos. Del mismo modo, revisa las distintas alternativas que han surgido para mitigar los riesgos jurisdiccionales ocasionados por este explosivo crecimiento de órganos de adjudicación internacional.

Palabras clave: multiplicación de cortes y tribunales internacionales, fragmentación, múltiples procedimientos.

* Abogado de la Universidad de Chile y LLM en Solución de Controversias Internacionales, Universidad de Ginebra y Graduate Institute of International and Development Studies. Se desempeña actualmente como profesor de Derecho Internacional en la Universidad Alberto Hurtado, en Chile. Correo electrónico: carlos.bellei@mids.ch. Dirección postal: Leopoldo Urrutia 2000, Departamento 1106, Nuñoa, Región Metropolitana, Santiago (Chile).

Para citar este artículo: Bellei Tagle, Carlos, "Consecuencias jurisdiccionales asociadas a la multiplicación de tribunales internacionales: ¿en qué consisten los potenciales riesgos?”, Anuario Colombiano de Derecho Internacional (ACDI), 2016, 9, pp. 17-49. Doi: dx.doi.org/10.12804/acdi9.1.2016.01 
Jurisdictional Consequences Associated with the Multiplication of International Tribunals: What Are the Potential Risks?

Abstract: The dispute resolution system is an essential aspect in order to grant efficacy to international law. In recent years various transformations have been tried, the most significant of which are the multiplication of international courts and tribunals. This work explores the different effects this result has generated, concentrating on some considered negative. Likewise, it reviews different alternatives that have arisen to mitigate the jurisdictional risks occasioned by the explosive increase in organs of adjudication.

Keywords: multiplication of international courts and tribunals, fragmentation, multiple proceedings.

Consequências jurisdicionais associadas à multiplicação de tribunais internacionais: em que consistem os potenciais riscos?

Resumo: O sistema de solução de controvérsias é um aspecto essencial para outorgar eficácia ao direito internacional. Durante os últimos anos, tem experimentado várias transformações, a mais significativa de toda a multiplicação de cortes e tribunais internacionais. Este trabalho explora os distintos efeitos que dito processo tem gerado, centrando-se em aqueles considerados como negativos. Da mesma maneira, revisa as distintas alternativas que têm surgido para mitigar os riscos jurisdicionais ocasionados por este explosivo crescimento de órgãos de adjudicação internacional.

Palavras-chave: multiplication of international courts and tribunals, fragmentation, multiple proceedings.

\section{A modo de aproximación}

Una de las más trascendentales transformaciones experimentadas por el derecho internacional público durante las últimas décadas ha sido el cambio de paradigma producido en el interior del sistema de solución de 
controversias. Históricamente, los Estados fueron renuentes a someter sus disputas ante órganos judiciales internacionales, optando preferentemente por la búsqueda de soluciones a través de mecanismos que les permitiesen ejercer cierto grado de control sobre el procedimiento y los resultados, típicamente la mediación, conciliación o la negociación directa (es decir, a través de medios políticos).

En la actualidad, la comunidad internacional ha sido testigo de una alteración de dicha concepción, dándose paso a un fenómeno al que se le denomina indistintamente 'proliferación' o 'multiplicación', caracterizado por un explosivo aumento en el número de tribunales y cortes. Esta evolución hacia un nuevo estadio de desarrollo representa un punto de inflexión que contribuye al proceso de institucionalización y legitimación del derecho internacional en su conjunto. Sin embargo, con estas externalidades que han de entenderse como positivas, han surgido varias inquietudes que dan cuenta de los diversos riesgos y problemas jurisdiccionales que tal crecimiento podría estar generando. Efectivamente, al no existir un mecanismo centralizado de creación de estos nuevos órganos judiciales, el proceso de atribución de sus competencias ha carecido del nivel de coordinación adecuado que permita delimitarlas satisfactoriamente. Como resultado, es posible identificar situaciones en las cuales la jurisdicción de más de un tribunal o corte se extiende sobre una misma tipología de controversias. Esto acarrea dos potenciales efectos adversos: por un lado, el riesgo de fragmentación del derecho internacional sustantivo, como consecuencia de la posible dictación de sentencias contradictorias por parte de distintos tribunales; y por el otro, el desencadenamiento de conflictos de jurisdicción, derivados de la existencia de jurisdicciones concurrentes o superpuestas, y que se manifiestan en la existencia de procedimientos paralelos o sucesivos.

Con este cuadro inicial en mente, el presente artículo explora los riesgos para el ejercicio de la función jurisdiccional asociados a la multiplicación de foros, sugiriendo distintas alternativas para atenuarlos. Para ello, la primera parte da cuenta del significativo cambio en la adjudicación internacional generado a partir del incremento en el número de alternativas jurisdiccionales disponibles. En un segundo nivel de análisis, el trabajo se concentra en el estudio particular de los principales riesgos, llámese fragmentación del derecho internacional, y los potenciales conflictos de jurisdicción. Al final, algunas reflexiones son planteadas a modo de conclusión. 


\section{La multiplicación de tribunales y cortes internacionales: un significativo cambio en el panorama de la adjudicación internacional}

Por muchos años, la Corte Internacional de Justicia (CIJ) fue el único tribunal internacional de carácter permanente investido con jurisdicción general para el conocimiento de todo tipo de disputas interestatales de contenido jurídico. Así, era relativamente sencillo identificar un conjunto único de reglas y principios aplicables a la resolución de un conflicto específico, permitiendo que la interpretación y aplicación de tales normas fuese realizada de manera más o menos consistente. ${ }^{1}$

Pero, como adelantamos, debido a una serie de complejos factores, este panorama ha cambiado de manera sustancial, generándose un novedoso escenario caracterizado por la existencia de una mayor predisposición de los Estados para someter sus disputas a mecanismos internacionales de adjudicación. Dando cuenta de esta transformación, el Proyecto sobre Tribunales y Cortes Internacionales ${ }^{2}$ ha elaborado un esquema gráfico en el que se identifican un total de 43 instituciones judiciales de naturaleza permanente (no todas actualmente vigentes), a lo que se suman otros 82 organismos entre aquellos constituidos de manera ad hoc, cuasijudiciales y de control de implementación de ciertas convenciones internacionales. El contraste es fácil de percibir si consideramos que con anterioridad a la década de los noventa - momento en el cual la creación de órganos judiciales alcanzó su momento más efervescente- el sistema internacional solo contaba con seis instituciones permanentes, ${ }^{3}$ más

\footnotetext{
1 Dupuy, Pierre-Marie, "The danger of fragmentation or unification of the international legal system and the International Court of Justice", Journal of International Law and Politics, 1999, 31, (4), pp. 791-792.

2 Project on International Courts and Tribunals, New York University, University College London, and Foundation for International Environmental Law and Development. La información se encuentra disponible en http://www-pict-pcti.org, consulta del 10 de julio de 2014.

3 Estos eran: Corte Internacional de Justicia, Corte de Justicia de la Unión Europea, Corte Europea de Derechos Humanos, Corte de Justicia de la Unión Aduanera de Benelux, Corte Interamericana de Derechos Humanos y Corte de Justicia de las Comunidades Andinas.
} 
una serie de tribunales conformados $a d h o c^{4}$ y algunos otros de naturaleza semipermanente. $^{5}$

Numerosas explicaciones han sido planteadas para intentar desentrañar los factores que condujeron a la vertiginosa creación de estos nuevos órganos judiciales. ${ }^{6}$ En síntesis, en nuestra opinión, se trata de un asunto que encuentra sus causas en circunstancias que entremezclan consideraciones históricas, políticas y jurídicas. El colapso de la Unión Soviética y el consiguiente fin del bipolarismo y de la permanente tensión multilateral produjeron una transformación sistémica de las relaciones internacionales, que puso término a la permanente desconfianza expresada fundamentalmente por los países de la órbita socialista hacia la adjudicación internacional. Prueba de ello es que, luego de la caída de la Cortina de Hierro, numerosas repúblicas alineadas con la antigua Unión Soviética comenzaron sucesivamente a aceptar la jurisdicción de diferentes tribunales y cortes internacionales ${ }^{7}$ y a ser, incluso, activos litigantes ante dichos foros. ${ }^{8}$ Desde un punto de vista político, el término de la Guerra Fría puso

4 Por ejemplo, los numerosos tribunales arbitrales constituidos al amparo de la Corte Permanente de Arbitraje.

5 Como el Tribunal de Reclamaciones Irán-Estados Unidos.

$6 \quad \mathrm{Al}$ respecto, destacan los trabajos de Romano, Cesare, "The proliferation of international judicial bodies: the pieces of the puzzle", Journal of International Law and Politics, 1999, 31, (4), pp. 709-751; y Shany, Yuval, The competing jurisdiction of international courts and tribunals, Oxford University Press, Oxford, 2003.

7 Romano, “The proliferation...”, op. cit., pp. 733-734. En el caso de la CIJ, a partir de mediados de los noventa las siguientes exrepúblicas socialistas efectuaron declaraciones unilaterales de aceptación de su jurisdicción, al amparo de lo prescrito en el artículo 36.2 de su Estatuto: Estonia (1991), Hungría (1992), Georgia (1995), Polonia (1996), Eslovaquia (2004), Lituania (2012). Fuente: http://www.icj-cij.org/jurisdiction/index. php?p1 =5\&p2=1\&p3=3, consulta del 10 de junio de 2014; tratándose del Convenio de Washington (CIADI), han adherido, entre otras: Armenia, Azerbaiyán, Bielorrusia, Estonia, Federación de Rusia, Georgia, Kazajistán y Lituania (todas en 1992), República Checa (1993), Eslovenia y Uzbekistán (1994), Bosnia y Herzegovina y Letonia (1997), Macedonia y Ucrania (1998), y Bulgaria (2000). Fuente: https://icsid.worldbank.org/ICSID/FrontServlet, consulta del 13 de junio de 2014.

8 A modo ejemplar, tres paradigmáticas disputas sirven para representar este nuevo escenario: la disputa medioambiental surgida entre Hungría y Eslovaquia conocida como Gabčlkovo-Nagymaros; la controversia desatada entre Bosnia y Herzegovina y Yugoslavia respecto de la Aplicación de la Convención sobre la Prevención y Sanción del Delito de Genocidio; y el caso entre Croacia y Serbia respecto a la aplicación de la misma Convención sobre Genocidio. Todas estas disputas fueron referidas al conocimiento de la CIJ. 
a los Estados en la necesidad de garantizar un mayor nivel de compromiso con el respeto de las reglas jurídicas internacionales, como herramienta indispensable para afianzar la profundización de las relaciones entre pares. En términos jurídicos, la multiplicación de tribunales internacionales constituye una reacción esperable si consideramos el proceso de expansión experimentado por el derecho internacional hacia áreas tradicionalmente excluidas de su alcance, ya fuere porque estas se encontraban reservadas a la jurisdicción doméstica (asuntos criminales) o porque simplemente existía un vacío normativo (cuestiones medioambientales). Como una razonable consecuencia, se hizo indispensable contar con un sistema de adjudicación internacional compuesto por órganos dotados de mayores niveles de especialización, capaces de entregar respuestas adecuadas ante el surgimiento de controversias cada vez más complejas y sofisticadas, lo que marca un contraste con aquellas jurisdicciones generales, como la que ejerce la $\mathrm{CIJ} .{ }^{9}$ Por último, podemos agregar algunas razones de índole más bien prácticas. Así, el hecho de que la jurisdicción de la CIJ se encuentre restringida exclusivamente a la comparecencia de Estados es una importante limitante en relación con los nuevos foros, varios de los cuales han permitido a organizaciones internacionales y particulares presentar reclamaciones, ser sujetos pasivos de tales procedimientos o intervenir en calidad de amicus curiae.

\subsection{Más allá de los números}

Los cambios orgánicos a los que hacemos referencia no se reducen a un asunto exclusivamente numérico, sino que ponen en evidencia una realidad mucho más compleja, a la que es necesario referirse brevemente. En este contexto, consideramos que el reciente robustecimiento de la red de tribunales y cortes es la expresión de por lo menos tres fundamentales transformaciones.

En primer lugar, da cuenta de un incremento en la utilización de la adjudicación como mecanismo de resolución pacífica de controversias internacionales que involucran a los Estados. Estadísticamente, no existen

\footnotetext{
9 Pertenecen a esta clase de nuevos órganos especializados el Tribunal sobre Derecho del Mar (1982), los tribunales penales establecidos de manera ad hoc (por ejemplo, los de la ex-Yugoslavia, Ruanda y el Líbano), el sistema de solución de controversias de la Organización Mundial del Comercio (1994), la Corte Penal Internacional (1998) y la Corte Africana de Derechos Humanos y de los Pueblos (1998), entre otros.
} 
dudas de que la cantidad de disputas de este tipo que son sometidas a órganos judiciales ha aumentado significativamente. ${ }^{10}$ La razón es de toda lógica, si tenemos en mente que es precisamente este cambio de actitud frente al arreglo judicial lo que abrió paso a que nuevos tribunales y cortes pasaran a incorporarse al sistema. Pero este incremento en la judicialización también se refleja si observamos la carga de trabajo de aquellos tribunales que temporalmente operan desde antes que la proliferación se produjese. ${ }^{11}$

En segundo término, refleja una tendencia hacia el establecimiento de procedimientos obligatorios de solución de controversias, en el entendido de que varios de los nuevos órganos judiciales han sido investidos con jurisdicción compulsoria respecto de las partes que han suscrito sus respectivos instrumentos constitutivos. El ejemplo más claro lo encontramos en la Organización Mundial del Comercio (OMC): de acuerdo con el 'Entendimiento sobre Solución de Diferencias', en el momento en que se alcanza la membresía a la institución, cada nuevo integrante consiente automáticamente en el otorgamiento de jurisdicción a su sistema de resolución de conflictos, en relación con cualquier disputa vinculada a la normativa OMC, sin que sea necesario efectuar alguna declaración adicional, como normalmente acontece. ${ }^{12}$

10 Para confirmar esta premisa, bastaría con contabilizar las disputas que han sido referidas a nuevos órganos, como, por ejemplo, el Tribunal sobre Derecho del Mar: desde su entrada en vigencia (1994), 22 disputas han sido presentadas, sumadas a 2 procedimientos de naturaleza consultiva. Fuente: https:/ $/$ www.itlos.org/index.php?id $=37 \& \mathrm{~L}=0$, consulta del 31 de julio de 2014.

11 Entre los años 1970 y 1979, la CIJ fue requerida en un total de 9 casos contenciosos. En contraste, entre 1990 y 1999, se presentaron 35 demandas; y, desde 2000 a la fecha, acumula en sus registros 37 solicitudes del mismo tipo. Fuente: http://www.icj-cij.org/ docket/index.php?p1 $=3 \& p 2=3$, consulta del 25 de julio de 2014. Lo mismo se repite si consideramos la carga de trabajo del CIADI respecto de las disputas sobre inversiones: entre los años 1966 (entrada en vigor) y 1989, conoció 26 casos. Pero, a partir de 1990 y hasta finales de 2013, la cifra aumenta considerablemente alcanzando los 433 requerimientos registrados. Fuente: Secretaría del CIADI (2014-1): carga de casos del CIADI-Estadísticas. La información comentada se encuentra disponible en https://icsid.worldbank.org/ICSID/Fr ontServlet?requestType $=$ ICSIDDocRH\&actionVal=CaseLoadStatistics, consulta del 13 de mayo de 2014.

12 Entendimiento Relativo a las Normas y Procedimientos por los que se Rige la Solución de Diferencias en la OMC, de 1994, artículo 23.1. Este acuerdo marca una sustancial diferencia respecto de la mayoría de los mecanismos existentes, en los que se requiere del otorgamiento de un consentimiento específico de las partes que ante él desean someterse. 
Finalmente, la multiplicación de tribunales y cortes internacionales implica una expansión de la tradicional noción de justiciabilidad hacia nuevas áreas del derecho internacional. Durante décadas, los Estados establecieron ciertas limitaciones a la utilización de medios jurisdiccionales para resolver sus controversias, reservándolos para los asuntos que no comprometían sus intereses esenciales. ${ }^{13}$ Con el tiempo, esta idea fue abandonada, dando curso hacia una actitud mucho más favorable y receptiva respecto del arbitraje y del arreglo judicial. Se redujeron entonces los espacios materiales no cubiertos por la adjudicación, en paralelo a la evolución del derecho internacional hacia nuevas áreas de desarrollo. La confluencia de ambos factores - la incorporación de nuevas regulaciones y el levantamiento del veto respecto de asuntos antes no sometidos a conocimiento de órganos judiciales internacionales - sirvió para expandir notablemente el concepto de justiciabilidad, haciendo necesario el establecimiento de nuevos tribunales y cortes capaces de absorber la mayor demanda en estas nuevas áreas del derecho.

\subsection{Visiones que se contraponen}

Como advertimos, la proliferación de foros internacionales ha generado discusiones en torno a relevantes aspectos en la esfera del derecho internacional. El diagnóstico compartido es que este proceso se ha desarrollado con prescindencia de un marco institucional debidamente organizado, y que esta particular característica acarrea varias consecuencias teóricas y prácticas. Especialmente útil es un párrafo de la sentencia pronunciada por el Tribunal Penal para la Ex-Yugoslavia (TPIY) en el famoso caso Tadic, en el cual estas inquietudes fueron nítidamente sintetizadas:

El derecho internacional, debido a que carece de una estructura centralizada, no contempla un sistema judicial integrado que opere sobre la base de una división ordenada de trabajo entre varios tribunales, en donde ciertos aspectos o componentes de la jurisdicción [...] puedan ser centralizados o conferidos a uno de ellos, pero no a los demás. En el derecho internacional, cada tribunal constituye un sistema autónomo (a menos que exista disposición en contrario). ${ }^{14}$

13 Lauterpacht, Hersch, The function of law in the international community (introduction Martii Koskenniemi), Oxford University Press, Oxford, 2011, p. 7.

14 Prosecutor v. Tadic, ICTY, Cámara de Apelaciones, Decisión sobre la moción de apelación interlocutoria sobre jurisdicción presentada por la defensa, Caso No IT-94-1, 1995, párr. 11. 
Es esta noción de autonomía de cada nuevo órgano judicial que se incorpora al sistema la razón fundamental de preocupación académica. El aislamiento en que cada tribunal desempeña sus funciones, sumado a la inexistencia de vínculos formales de coordinación entre estos nuevos órganos, genera una serie de consecuencias que afectan el ejercicio de la función jurisdiccional, cuando analizamos el panorama desde un punto de vista holístico. Sin embargo, como suele suceder con transformaciones complejas, suelen distinguirse diferentes posiciones que ponen el acento en puntos contrapuestos. Las ejemplificaremos en palabras de dos expresidentes de la CIJ. El exjuez Buergenthal prefiere destacar los aspectos positivos de la proliferación de tribunales y cortes. En su opinión, se trata de una consecuencia previsible derivada de la mayor aceptación de los Estados hacia el arreglo judicial, al valorarla como una alternativa viable y efectiva para la resolución de controversias, lo que no puede sino considerarse como una externalidad positiva. ${ }^{15}$ Profundizando esta línea de razonamiento, en nuestra opinión, es este cambio de paradigma lo que ha posibilitado la incorporación de nuevos organismos especializados, cuya competencia escapa a la tradicional experticia general con la que contaban la mayoría de los tribunales y cortes. Tal es el caso de los órganos establecidos para conocer de controversias sobre inversiones, comercio, medio ambiente y derechos humanos. Esta diversificación de alternativas ${ }^{16}$ también ha permitido reducir aquellas zonas grises que en el pasado daban cuenta de esferas de convivencia que se encontraban alejadas del control judicial. ${ }^{17}$

Además, el creciente número de disputas resueltas a través de estos mecanismos jurisdiccionales contribuye al proceso de institucionalización del derecho internacional, por medio de diferentes avenidas. La más importante tiene que ver con el fortalecimiento de la convicción de los

15 Buergenthal, Thomas, "Proliferation of international courts and tribunals: is good or bad?", Leiden Journal of International Law, 2001, 14, (2), p. 272.

16 Refiriéndose a la multiplicación, Remiro Brotóns afirma: "Esta proliferación, tal y como se predica de la misma expansión y diversificación material del derecho internacional, es un signo de madurez, al ofrecer vías para la solución definitiva y vinculante de diferencias y/o abrir paso a la persecución de crímenes internacionales, pero es también una nueva dificultad para la unidad y coherencia del sistema jurídico internacional, un riesgo de fragmentación, por la falta de jerarquía formal entre unos y otros tribunales y la posibilidad de decisiones contradictorias, especialmente cuando sus respectivos ámbitos de competencia son tangentes o secantes". Remiro Brotóns, Antonio et al., Derecho internacional, Tirant lo Blanch, Valencia, 2007, p. 84.

17 Dupuy, “The danger...”, op. cit., p. 796. 
Estados en cuanto a que la eficacia del derecho internacional puede ser incrementada mediante la aplicación efectiva de las reglas jurídicas. Esto ha permitido un valorable tránsito desde una cultura más bien declarativa de derechos hacia otra en la cual la aplicación de reglas y principios se garantiza mediante la acción jurisdiccional de un tercero imparcial, al que las partes se someten de manera voluntaria para solucionar un conflicto. ${ }^{18}$

Desde el otro lado del espectro, el exjuez Guillaume ha optado por enfatizar los problemas ocasionados por la multiplicación, al firmar que el crecimiento en el número de tribunales y cortes podría poner en peligro la unidad e integridad del derecho internacional, y como resultado, su rol regulador de las relaciones internacionales. En sus palabras, sería inconveniente crear nuevos órganos judiciales sin que primero exista una revisión exhaustiva de si las funciones que potencialmente se les conferirían podrían ser desempeñadas por tribunales ya existentes. ${ }^{19}$ Es precisamente esta premisa respecto de los riesgos de la multiplicación el foco central de atención y reflexión de este artículo en lo sucesivo.

\section{Posibles riesgos asociados a la proliferación de tribunales y cortes internacionales}

Existe consenso en que el exponencial crecimiento de tribunales y cortes puede dar lugar al surgimiento de ciertas consecuencias negativas para el sistema de justicia internacional. En muchos casos, se trata más bien de costos naturales derivados del drástico cambio en la escena de la adjudicación internacional, por esto lo realmente relevante consiste en la determinación de la manera en que dichos riesgos son morigerados. Estas potenciales consecuencias negativas se encuentran estrechamente relacionadas con el descentralizado método de creación de los nuevos órganos judiciales, alejado de saludables niveles de coordinación e interacción institucionalizada. A este respecto, dos son los principales riesgos que enfrenta el sistema: por un lado, la posibilidad de fragmentación del derecho internacional sustantivo; y por el otro, el surgimiento de los denominados conflictos de

\footnotetext{
18 Una profundización de lo que venimos comentando puede revisarse en Schwebel, Stephen M., "Address to the General Assembly of the United Nations", 1998, en http:// www.icj-cij.org/presscom/files/7/3007.pdf, consulta del 12 de junio de 2014.

19 Guillaume, Gilbert, "Speech to the General Assembly of the United Nations", 2001, en http://www.icj-cij.org/court/index.php?pr=82\&pt=3\&p1=1\&p2=3\&p3=1\&PHPSES $\operatorname{SID}=$, consulta del 11 de mayo de 2014 .
} 
jurisdicción, derivados de la existencia de jurisdicciones potencialmente superpuestas.

\subsection{E1 riesgo de fragmentación del derecho internacional sustantivo}

La probable fragmentación de las reglas de derecho internacional ha sido identificada como una posible externalidad negativa emanada de la multiplicación. ${ }^{20}$ No existiendo una estructura de tipo jerárquico que ordene las relaciones orgánicas entre las diferentes instituciones judiciales, sumado a la inexistencia de la regla del precedente, existe un riesgo efectivo de que sucesivas disputas que involucren similares normas y principios puedan ser resueltas de manera divergente — incluso contradictoria- por distintos tribunales y cortes internacionales. La premisa de que casos similares serán tratados en sede judicial de manera semejante constituye una aspiración política deseable, que se vincula con la certeza y la legitimidad de cualquier sistema de justicia. Estos riesgos se profundizan si consideramos que cada uno de los nuevos órganos conforma un régimen, que ha de entenderse como autónomo, en el sentido de que su operación se produce en la práctica en un contexto de aislamiento respecto de los restantes. ${ }^{21}$

20 Tanto es así que el trabajo que más profundiza sobre el fenómeno de la fragmentación - tanto desde un punto de vista institucional como relativo al derecho internacional sustantivo — ha sido elaborado por la Comisión de Derecho Internacional de las Naciones Unidas, y se encuentra contenido en el documento "Fragmentation of international law: difficulties arising from the diversification and expansion of international law", Report of the Study Group finalized by Martii Koskenniemi, A/CN.4/L.682, 2006. Este documento reconoce que frente al fenómeno de la fragmentación existen opiniones doctrinarias divergentes, al señalar: "Algunos autores han sido altamente críticos de lo que han visto como la erosión del derecho internacional general, la emergencia de jurisprudencia contradictoria, el forum-shopping, y la pérdida de seguridad jurídica. Otros han observado aquí un problema meramente técnico que ha emergido naturalmente con el incremento de la actividad jurídica internacional y que puede controlarse mediante la racionalización técnica y la coordinación” (párr. 9).

21 Si bien, como anota Rodiles, la expresión "régimen autónomo" fue utilizada por primera vez por la Corte Permanente en el caso Wimbledon (1923), fue en la disputa sobre el Personal diplomático y consular en Teherán (Estados Unidos v. Irán) en donde la CIJ hizo referencia expresa a la existencia de una rama particular del derecho internacional —el diplomático_ con características autónomas respecto de las restantes. Rodiles, Alejandro, "La fragmentación del derecho internacional: ¿riesgo u oportunidad para México?", Anuario Mexicano de Derecho Internacional, 2009, IX, p. 384. Pero esta noción de autonomía de la cual 
Sin embargo, creemos que la reflexión en torno a la potencial fragmentación del derecho como consecuencia de la proliferación debe contener ciertos matices y precisiones, que serán abordados a continuación.

\subsubsection{Decisiones contradictorias emanadas de diferentes órganos judiciales internacionales}

Si revisamos la actividad de los principales tribunales internacionales, podremos efectivamente constatar divergentes aplicaciones respecto de un mismo conjunto de reglas y principios jurídicos. Uno de los ejemplos más paradigmáticos de esta situación — en este caso referido a las normas sobre atribución de responsabilidad del Estado por actos cometidos por sus fuerzas militares- lo encontramos en los casos Tadic, de las Actividades militares y paramilitares en Nicaragua y Aplicación de la Convención que Sanciona el Genocidio.

En Prosecutor v. Tadic, 22 el TPIY discrepó expresamente de una interpretación anterior de la CIJ, y utilizó el denominado test del 'control general' para considerar que algunos actos cometidos por los acusados podrían ser propiamente atribuidos a la República Federal de Yugoslavia. Casi diez años antes, la CIJ en el caso Nicaragua había sido partidaria del empleo de un estándar más estricto en relación con una situación similar. En dicha oportunidad, la Corte dictaminó que los Estados Unidos no podían ser jurídicamente responsabilizados por acciones cometidas por paramilitares en Nicaragua a menos de que se demostrase que tenían un "control efectivo" sobre las actividades de dichos grupos. ${ }^{23}$ La mencionada saga continuó años más tarde en Aplicación de la Convención sobre Genocidio,

estarían investidos los distintos tribunales y cortes internacionales, equiparable en cierto sentido a una especie de 'aislamiento', ha creado —en opinión de Fernández Liesa— la "falsa imagen" del derecho internacional como una mera sumatoria de subsistemas autónomos "equipados con sistemas jurisdiccionales que funcionarían con independencia del ordenamiento internacional general", en circunstancias en que "los tribunales no aplican ordenamientos independientes del derecho internacional general y deben aplicar este cuando sea pertinente. Los tribunales no son autónomos del derecho internacional general". Fernández Liesa, Carlos R., "La proliferación de tribunales internacionales en el espacio iberoamericano", Revista Electrónica de Derecho Iberoamericana, 2008, 2, (2), p. 13.

22 Prosecutor v. Tadic, ICTY, Cámara de Apelaciones, Sentencia, Caso No IT-94-A-1, 1999, párrs. 115 y 137.

23 Actividades militares y paramilitares en y en contra de Nicaragua (Nicaragua v. Estados Unidos), Mérito, ICJ Reports, 1986, párrs. 110-115. 
cuando la CIJ reafirmó su posición inicial y consideró que la aplicación de un test de 'control general' para atribuir responsabilidad al Estado sobre ciertas actividades militares escapaba del alcance del derecho que regula esta materia. $^{24}$

Recientemente, la misma materia fue objeto de análisis por parte de la Corte Penal Internacional, en el caso Prosecutor v. Lubanga. ${ }^{25}$ En dicha ocasión, la Sala de Primera Instancia siguió en su interpretación al TPIY, señalando que el test de control general resulta suficientemente apropiado para evaluar la responsabilidad del acusado. Como hemos mencionado, esta postura menos estricta en cuanto a su estándar de valoración difiere de la adoptada por la CIJ. ${ }^{26}$

La situación relatada es notable por dos razones: por una parte, porque da cuenta de interpretaciones notoriamente contradictorias acerca de una misma regla de derecho internacional —en este caso, la regulación de la atribución de responsabilidad del Estado por actos cometidos por órganos que operan de facto- entre dos órganos judiciales establecidos por las Naciones Unidas; ${ }^{27}$ y por la otra, debido a que es una de las escasas situaciones en las cuales colisiones frontales de este tipo se han producido.

Existen otros ejemplos relacionados con la aplicación de otro tipo de reglas jurídicas. Tal es el caso del tratamiento del alcance de las reservas que efectúan los Estados al momento de suscribir una convención internacional, cuando estos pretenden establecer ciertas limitaciones a su aplicación. En Fosfatos en Marruecos, la Corte Permanente de Justicia

24 Aplicación de la Convención sobre la Prevención y Sanción del Delito de Genocidio (Bosnia y Herzegovina v. Serbia y Montenegro), Mérito, ICJ Reports, 2007, párr. 406.

25 Situation in the Democratic Republic of the Congo in the case of the Prosecutor v. Thomas Lubanga Dyilo, ICC, Sala de Primera Instancia, Decisión de acuerdo con el artículo 74 del Estatuto, Caso ICC-01/04-01/06, 2012.

$26 \mathrm{Al}$ respecto, Böhm señala que las dificultades de interpretación ameritan preguntarse sobre si deben considerarse distintos tests dependiendo del ámbito o contexto. Böhm, María Laura, "Informe del x Encuentro del Grupo Latinoamericano de Estudios sobre Derecho Penal Internacional”, en Ambos, Kai et al. (Eds.), Análisis de la primera sentencia de la Corte Penal Internacional: el caso Lubanga, Fundación Konrad Adenauer, 2014, p. 469.

27 De acuerdo con el artículo 92 de la Carta de las Naciones Unidas, la CIJ constituye su principal órgano judicial. A su turno, el TPIY fue establecido de manera ad hoc por el Consejo de Seguridad al amparo de las potestades contenidas en el capítulo VII de la Carta (Resolución 827, de 25 de mayo de 1993), para el castigo de los crímenes internacionales perpetrados en la antigua Yugoslavia. 
Internacional (CPJI) permitió tal clase de reservas, indicando que las declaraciones por medio de las cuales los Estados conferían jurisdicción obligatoria a la Corte constituían actos unilaterales que debían interpretarse de manera restrictiva. Como consecuencia, la jurisdicción otorgada solo podía extenderse dentro de los precisos límites establecidos en tales declaraciones. ${ }^{28}$ Más adelante, en la opinión consultiva sobre las Reservas a la Convención para la Prevención y Sanción del Delito de Genocidio, la CIJ agregó un nuevo antecedente, al estimar que un Estado que efectúa una reserva puede ser considerado como parte de una convención, pero siempre y cuando dichas reservas no fueren incompatibles con su objeto y propósito. ${ }^{29}$ Similar discusión se ha llevado a cabo más recientemente en el campo de los tribunales encargados de la protección de los derechos humanos, en este caso, en el interior de la Corte Europea (CEDH). En Loizidou, la Corte se pronunció sobre la posibilidad de que los Estados pudiesen incorporar reservas al texto de la Convención Europea de Derechos Humanos, con miras a limitar territorialmente el alcance de la competencia que le otorgaban en ese entonces a la vigente Comisión Europea de Derechos Humanos. Lo interesante para nuestro análisis es que su decisión se distanció de lo sentenciado por la CPJI y la CIJ, señalando que, en el contexto específico de la protección de los derechos humanos, una reserva de este tipo no podía ser permitida, a pesar de constituir un acto unilateral del Estado. ${ }^{30}$ En opinión de la CEDH, existirían diferencias fundamentales en las esferas en las que operan estos órganos judiciales - la CIJ y la propia $\mathrm{CEDH}$ - que hacen aconsejables que las reglas generales sobre reservas a tratados elaboradas por la CIJ no se apliquen de similar modo en el ámbito de los derechos humanos. ${ }^{31}$

28 Fosfatos en Marruecos (Italia v. Francia), Objeciones preliminares, PCIJ Series A/B N ${ }^{\circ} 74$, 1938, p. 23.

29 Reservas a la Convención para la Prevención y Sanción del Delito de Genocidio, Opinión consultiva, ICJ Reports, 1951, p. 29.

30 Loizidou v. Turkey, Preliminary objections, ECHR Case No 15318/89, 1995, párrs. 84-85.

31 En todo caso, es pertinente recordar que la Convención Europea de Derechos Humanos contiene su propio régimen sobre el tratamiento de reservas, en su artículo 57 (a la fecha del caso, art. 64). De acuerdo con este, las reservas son permitidas en la medida en que una ley en vigor en el territorio del Estado respectivo esté en desacuerdo con la disposición que se reserva, pero sin que estén permitidas aquellas de carácter general. 


\subsubsection{La necesaria relación de causalidad}

Los casos mencionados están por cierto lejos de constituir evidencia suficiente que permita concluir que es la existencia de múltiples foros judiciales el factor que conduce (o al menos que contribuye sustancialmente) a la fragmentación del derecho internacional sustantivo, mediante la comprobación de la existencia de decisiones contradictorias. Para poder atribuir a la proliferación dicha consecuencia, consideramos fundamental constatar la concurrencia de una relación de causalidad. Así, la cuestión clave consiste en determinar si el derecho internacional puede experimentar fragmentación aun en ausencia del proceso de proliferación de órganos judiciales, lo que podrá ser evaluado en propiedad cuando solo exista una alternativa disponible para resolver una determinada categoría de disputas. Pero también cuando apreciamos la evolución y desarrollo temporal de la jurisprudencia emanada de un mismo tribunal. Sobre esto último, es necesario advertir que cualquier posible evaluación debe necesariamente recordar que en el derecho internacional no existe la regla del precedente, aun cuando en general los diversos foros existentes tienden a desarrollar una suerte de 'jurisprudencia constante'. Así, es perfectamente posible —y a menudo sucede- que un mismo tribunal o corte realice interpretaciones y aplicaciones contradictorias o diferentes en el tiempo respecto de un mismo conjunto de reglas jurídicas, pues no se encuentra obligado por sus decisiones anteriores. ${ }^{32}$

Existe en ese sentido evidencia que proviene de la práctica de la CIJ, cuando ha conocido asuntos relativos a la demarcación de fronteras marítimas. En dicho contexto, ha existido una histórica tensión entre el uso del método de la equidistancia, en contraposición a la búsqueda de soluciones equitativas que tomen en cuenta todas las circunstancias relevantes. Este asunto ha sido discutido arduamente durante las últimas décadas. En el caso de la Plataforma continental del Mar del Norte (1969), la Corte resolvió mediante la aplicación de principios de equidad, y tomando en cuenta las circunstancias y factores relevantes. ${ }^{33}$ Posteriormente, repitió dicha

\footnotetext{
32 El efecto relativo de la sentencia se consagra en diversos instrumentos internacionales relativos al funcionamiento de tribunales y cortes. Resaltan el artículo 59 del Estatuto de la CIj; el 53(1) del Convenio de Washington en el marco del arbitraje de inversiones del CIADI; el 33(2) del Estatuto del Tribunal sobre Derecho del Mar; y el 37 del Estatuto de la Corte Centroamericana de Justicia, entre otros.

33 Plataforma continental del Mar del Norte (República Federal de Alemania v. Dinamarca/ Países Bajos), Mérito, ICJ Reports, 1969, párr. 101.
} 
fórmula en los casos de la Plataforma continental entre Tunes y Libia (1982), ${ }^{34}$ y en su decisión sobre el Golfo de Maine (1984), ${ }^{35}$ aunque en este último caso con algunos matices. No obstante, a partir del caso de la plataforma continental entre Libia y Malta (1985), ${ }^{36}$ la Corte adoptó como criterio la línea de la equidistancia en tanto inicio de la delimitación, para luego y a partir de cierto punto geográfico aplicar principios equitativos que tomasen en cuenta todas las circunstancias relevantes, como la configuración general de la costa. Luego, en la Delimitación marítima entre Groenlandia y Jan Mayen (1993), ${ }^{37}$ la CIJ estableció una regla que pretendió ser aplicable de ahí en adelante a toda situación similar, señalando que primero era necesario trazar una línea equidistante, para luego ajustarla tomando en cuenta todas las circunstancias relevantes, especialmente la configuración del borde costero. La confirmación de esta solución se produjo en el caso de la Delimitación marítima entre Qatar y Babréin $(2001)^{38}$ y en la Delimitación marítima en el Mar Negro (2009). ${ }^{39}$ De esta forma, la solución inicialmente adoptada en 1969 fue paulatinamente siendo dejada de lado (sin señalarlo de manera explícita), dando paso a una solución unificada y específica. ${ }^{40}$

Fuera de la jurisdicción general de la CIJ, también es posible identificar casos en los cuales existe jurisprudencia contradictoria. Esta situación es clara si analizamos en el contexto del arbitraje de inversiones la práctica del CIADI. Por ejemplo, luego del violento colapso de la economía argentina en 2001, que desató una severa crisis política, económica y social, varias demandas fueron presentadas en su contra ante el CIADI, la mayoría de las cuales fueron basadas en el tratado bilateral de protección de inversiones entre dicho país y los Estados Unidos. Se trató de peticiones respecto de la violación de una serie de derechos establecidos a favor de los inversionistas extranjeros, quienes alegaban que las medidas adoptadas por el

\footnotetext{
34 Plataforma continental (Tunes v. Libia), Mérito, ICJ Reports, 1982, párr. 133.

35 Delimitación de la frontera marítima en el Golfo de Maine (Canadá v. Estados Unidos), Mérito, ICJ Reports, 1984, párr. 241.

36 Plataforma continental (Libia v. Malta), Mérito, ICJ Reports, 1985, párr. 79.

37 Delimitación marítima en el área entre Groenlandia y Jan Mayen (Dinamarca v. Noruega), ICJ Reports, 1993, párrs. 91-92.

38 Delimitación marítima y cuestiones territoriales (Qatar v. Bahréin), Mérito, ICJ Reports, 2001, párr. 249.

39 Delimitación marítima en el Mar Negro (Rumania v. Ucrania), Mérito, ICJ Reports, 2009, párr. 219.

40 Guillaume, "Speech to the General...", op. cit., p. 12.
} 
gobierno para hacer frente a la catástrofe habían perjudicado severamente sus inversiones. Frente a varias de estas demandas, Argentina se defendió argumentando la existencia de un estado de necesidad, que había hecho imprescindible la adopción de tales medidas, a riesgo de que la situación se continuase agravando. Numerosos paneles fueron entonces conformados. Lo interesante es que en el primero de los casos, CMS v. Argentina, el respectivo tribunal arbitral desechó la alegación basada en la existencia del estado de necesidad, en tanto circunstancia excluyente de responsabilidad internacional. ${ }^{41}$ Sin embargo, el asunto se volvió confuso e incierto toda vez que un segundo panel arbitral constituido en $L G \otimes E v$. Argentina arribó a una conclusión diametralmente distinta, acogiendo la mencionada defensa, ${ }^{42}$ pese a tener en consideración idénticos antecedentes fácticos que el primero de los casos señalados.

Los ejemplos que hemos mencionado - aunque con las naturales prevenciones en el sentido de que unos obedecen a la práctica de un tribunal permanente (CIJ) mientras que los otros se refieren a tribunales que se conforman de manera ad hoc (CIADI) - sirven para confirmar un asunto que pareciera evidente en virtud de la inexistencia de la regla del precedente, pero que es útil para reforzar la argumentación que venimos desarrollando: en nuestra opinión, la proliferación de tribunales internacionales no constituye la causa eficiente de la fragmentación del derecho internacional sustantivo, en el entendido de que decisiones contradictorias pueden ser dictadas sucesivamente en el tiempo incluso por parte de un mismo tribunal. No es comprobable, entonces, la referida relación de causalidad.

Lo que sí consideramos acertado es atribuir a la multiplicación de foros el aumento en las posibilidades de aplicación contradictoria de similares reglas jurídicas. Como mencionamos, al no existir un mecanismo centralizado de creación de los nuevos tribunales, muchas veces estos han sido investidos con jurisdicciones concurrentes. Por ejemplo, es posible identificar posibles áreas de competencias superpuestas, por un lado entre, la CIJ y la Corte Permanente de Arbitraje, y por el otro, distintos órganos que ejercen jurisdicción especializada, como es el caso del Tribunal sobre Derecho del Mar (TDM) o el sistema de solución de controversias de la OMC. Esta situación evidentemente aumenta el riesgo de que asuntos

41 CMS Gas Transmission Company v. Argentina, Icsid Case No ARB/01/8, 2005, párr. 324

42 LG\&E Energy Corp. et al. v. Argentina, Decision on liability, Icsid Case $\mathrm{N}^{\circ} \mathrm{ARB} / 02 / 1$, 2007, párr. 226. 
regulados por similares normas y principios jurídicos puedan ser resueltos por distintos tribunales de manera contradictoria, pues cada uno de ellos es soberano para adoptar sus propias decisiones, y no cuenta con una obligación de fidelidad respecto de precedentes externos. De esta forma, cualquier intento serio por frenar la fragmentación pasaría por una reforma integral al sistema de adjudicación, desde un punto de vista orgánico y funcional, como, por ejemplo, la consagración de un procedimiento de apelación potencialmente bajo la responsabilidad de la CIJ. Como ello no parece factible en la actual escena, entendemos que el aumento de este riesgo en el contexto de la multiplicación de foros ha de estimarse como un costo necesario, un asunto marginal (a la luz de la escasa jurisprudencia existente hasta la fecha) e inevitable en medio de un escenario internacional caracterizado por vertiginosas transformaciones, en su mayoría llevadas a cabo sin niveles suficientes de coordinación institucional entre los distintos foros.

Por el momento, como bien recuerda Aznar Gómez, "la solución, relativamente simple y eficaz, que propone el grupo de estudio sobre la fragmentación de la CDI es el recurso al derecho de tratados codificado por la propia comisión en la Convención de Viena sobre derecho de los tratados de 1969", debido a que constituiría un marco de unidad respecto de la labor desempeñada por todos los nuevos regímenes que se incorporan al sistema. ${ }^{43}$

\subsection{Conflictos de jurisdicción}

Un segundo efecto adverso atribuido a la multiplicación de tribunales internacionales surge de la posibilidad recién comentada de que existan áreas de competencia concurrentes o superpuestas entre diferentes tribunales: se trata de los denominados conflictos de jurisdicción que, como veremos, sí constituyen un efecto directamente derivado de la proliferación.

El sistema de justicia internacional opera sobre la base de un conjunto de subsistemas que coexisten de manera autónoma y aislada. En este

43 El referido autor agrega un segundo principio básico "sin cuyo complemento la propia norma recogida en el artículo 26 de la Convención de Viena perdería gran parte de su sentido: el principio de reparación del daño causado", el que junto con la regla del pacta sunt servanda "son imprescindibles para la existencia de cualquier orden jurídico". Aznar Gómez, Mariano J., "En torno a la unidad sistémica del derecho internacional", Revista Española de Derecho Internacional, 2007, LIX, (2), p. 577. 
funcionamiento paralelo, encontramos tribunales que ejercen distintos tipos de jurisdicciones: universal o regional, general o especializada, a lo que se suma un conjunto de posibles combinaciones. ${ }^{44}$ Esta forma de estructuración es una de las mayores debilidades del sistema, puesto que, como mencionamos, al no existir una distribución ordenada de sus competencias, en muchos casos una misma controversia puede ser potencialmente presentada ante más de un foro, desatándose un conflicto jurisdiccional.

\subsubsection{Definiendo el conflicto}

Para que un conflicto de esta naturaleza se produzca en propiedad, entendemos que es necesario incorporar un elemento cualitativo adicional: un genuino conflicto solo podrá ocurrir entre alternativas que sean estimadas como viables y comparables. Así, dos o más jurisdicciones pueden entenderse como en conflicto solo si las partes en disputa pueden obtener resultados cualitativamente similares, con indiferencia de si someten la controversia a uno u otro foro.

Por ejemplo, en la contienda sobre el Pez espada entre Chile y la Comunidad Europea, dos instancias internacionales para la resolución de conflictos fueron requeridas en forma paralela - la OMC (por la Comunidad Europea) y el TDM (a solicitud de Chile)—, lo que a primera vista parece configurar un típico caso de conflicto de jurisdicciones. Pero, en estricto rigor, estimamos que se trata de una situación más bien aparente que real, pues en este caso las jurisdicciones no son estrictamente concurrentes. Ello es así debido a que ambos litigantes efectuaron una calificación jurídica distinta de los hechos que dieron origen a la disputa, y buscaron, por ende, soluciones divergentes: mientras que para la $\mathrm{Co}^{-}$ munidad Europea las medidas de conservación de la especie adoptadas por Chile fueron consideradas como atentatorias contra las normas de la OMC que regulan el libre comercio (fundamentalmente el impedimento de

44 Por ejemplo, algunos tribunales ejercen jurisdicción universal ratione personae y competencia general ratione materiae (CIJ, Corte Permanente de Arbitraje); otros han sido investidos con jurisdicción universal ratione materiae y competencia especializada ratione personae (TDM, órgano solución de controversias de la OMC, Corte Penal Internacional, CIADI, etc.); también hay cortes regionales con competencia general ratione materiae (Corte de Justicia del Caribe y Corte Centroamericana de Justicia); finalmente, existen otros dotados de competencia especializada ratione materiae (principalmente aquellos pertenecientes a regímenes de integración económica, como los procedimientos del NAFTA, Mercosur y las cortes sobre derechos humanos —Europea e Interamericana-). 
acceso a los puertos chilenos a barcos factoría españoles), Chile estimó que la extracción indiscriminada del pez espada — aun cuando fuese realizada en aguas internacionales, debido al carácter altamente migratorio de la especie- podía ser objeto de adopción de medidas conservativas al amparo de lo prescrito en la Convención de las Naciones Unidas sobre el Derecho del Mar. La causa de pedir en ambos procedimientos fue diferente, y del mismo modo, la potencial resolución de uno u otro caso tanto en el interior del sistema de solución de conflictos de la OMC como en el contexto del TDM también lo hubiere sido, al aplicar ambos distintas reglas jurídicas sustantivas. ${ }^{45}$

En cambio, un verdadero conflicto de jurisdicción sí que puede identificarse entre las competencias de la CIJ y del TDM. Esto se acrecienta si consideramos que la $\mathrm{CIJ}$ ha conocido en el pasado una serie de casos relacionados con disputas que hoy podrían ser también conocidas por el TDM. ${ }^{46}$ Todavía más, la propia Convención sobre Derecho del Mar designó como foros alternativos para conocer de disputas sobre su interpretación y cumplimiento tanto a la CIJ como al TDM (además de la posibilidad de recurrir ante procedimientos comunes de arbitraje) ${ }^{47}$ El riesgo de que ambas jurisdicciones entren en conflicto es entonces, no solo aparente, sino real.

\subsubsection{Consecuencias derivadas de los conflictos de jurisdicción}

El fenómeno descrito en el último apartado genera dificultades para la adjudicación internacional que podrían erosionar ciertos deseables valores, como la predictibilidad. Este potencial daño es posible debido a las dos consecuencias prácticas que provoca la existencia de jurisdicciones concurrentes: la práctica del forum shopping y la existencia de múltiples procedimientos, sean estos paralelos o sucesivos.

45 Ello no quita que puedan alcanzarse decisiones materialmente contradictorias, lo que habría sido comprobable si ambos procedimientos hubieren seguido el curso normal hasta su resolución y las partes no hubieren alcanzado un acuerdo extrajudicial para ponerles término. Lo que desmitifica es la existencia real de jurisdicciones concurrentes.

46 Por ejemplo, en Pesquerías (Reino Unido v. Noruega), ICJ Reports, 1951; Plataforma continental del Mar del Norte (Alemania v. Holanda; Alemania v. Dinamarca), ICJ Reports, 1969; Pesquerías (Reino Unido v. Islandia), ICJ Reports, 1974; Plataforma continental (Túnez v. Libia), ICJ Reports, 1982; y Delimitación marítima en el área entre Groenlandia y Jan Mayen (Dinamarca v. Noruega), ICJ Reports, 1993.

47 Artículo 287, Convención de las Naciones Unidas sobre el Derecho del Mar, 1982. 


\section{a) Forum shopping'}

Si existe más de un foro disponible para someter a resolución una controversia, en teoría las partes podrían llevar su reclamo indistintamente ante el órgano judicial que consideren más ventajoso para la protección de sus propios intereses. Este proceso unilateral de búsqueda y posterior selección del tribunal más apropiado se conoce con el nombre de forum shopping, y es probablemente la consecuencia más directa y clara de la proliferación de foros internacionales. En efecto, antes de producirse el comentado aumento en el número de tribunales y cortes internacionales, en la mayoría de los casos simplemente no existía un foro alternativo al cual recurrir, por lo que las posibilidades de elección de las partes eran inexistentes o muy escasas.

El forum shopping encuentra sustento en la reconocida autonomía de la voluntad de la que gozan los sujetos de derecho internacional, la que, conforme a lo dispuesto en el artículo 33.1 de la Carta de las Naciones Unidas, se extiende a la decisión sobre cuál mecanismo escoger al momento de resolver una controversia. En nuestra opinión, en la mayoría de los casos no existirá un riesgo para el sistema derivado de esta práctica. Las dificultades surgirán cuando una de las partes intente tomar una ventaja indebida respecto de la otra, incurriendo en un abuso de derecho o derechamente un quebrantamiento del principio de buena fe. Dos situaciones ejemplifican lo anterior: la primera tiene lugar cuando uno de los litigantes conduce la disputa simultáneamente ante dos o más foros comparables, y que por ende, pueden pronunciar decisiones contradictorias (procedimientos paralelos); la segunda situación se presenta cuando litigar ante uno de los foros alternativos sea claramente más apropiado que hacerlo ante los restantes, también competentes. Por ejemplo, si un Estado intentase referir una controversia relativa a supuestos incumplimientos de obligaciones contenidas en un acuerdo económico regional ante la CIJ, con la exclusiva finalidad de evadir la jurisprudencia constante del competente foro judicial económico regional: resulta evidente que el órgano judicial regional se encuentra en una mejor posición para conocer de la diputa que la CIJ. ${ }^{48}$

Situaciones tan evidentes como las descritas son muy difíciles de constatar. De ahí que los efectos nocivos del forum shopping se conciban

48 A esta clase de situaciones se refiere Shany, The competing jurisdiction..., op. cit., pp. $147-148$. 
más a nivel teórico que práctico. De todos modos, existen tres mecanismos útiles para las partes que desean limitar su ejercicio abusivo. El primero es el más sencillo, y consiste en que las partes alcancen un mutuo acuerdo en la identificación del tribunal que consideren más apropiado para resolver una determinada disputa. Este acuerdo puede plasmarse con anterioridad al surgimiento de la disputa (cláusula compromisoria) o bien luego de que esta se ha cristalizado (compromiso). Si la designación se efectúa ex ante, y de todos modos se contemplan varios foros alternativos, las partes habrán acordado de antemano que cualquiera de estos ha de entenderse como legítimo para recurrir. Ejemplo de lo anterior es el Tratado Americano de Soluciones Pacíficas (Pacto de Bogotá), que otorga un derecho de opción a las partes de recurrir a la CIJ o a un procedimiento arbitral, si las partes así lo disponen. ${ }^{49}$

El investir a un determinado tribunal o corte con jurisdicción exclusiva respecto de una determinada tipología de disputas es una segunda opción. El más paradigmático de los ejemplos lo encontramos en el sistema de solución de disputas de la OMC, que establece un impedimento para sus miembros de recurrir a cualquier otro foro para la resolución de controversias, siempre cuando estas guarden relación con infracciones a la normativa OMC. ${ }^{50}$ Una normativa similar se incluye en el tratado que establece la Unión Europea: los Estados miembros se comprometen a no presentar reclamaciones que involucren cualquier asunto contemplado en el referido acuerdo ante otro foro diferente al por este establecido. ${ }^{51}$ En ambos casos, la razón perseguida es el impedir que otros órganos judiciales apliquen el derecho propio de la OMC o comunitario. ${ }^{52}$

La tercera posibilidad que ha sido sugerida surge desde fuera del contexto del derecho internacional, específicamente de las jurisdicciones de algunos países de tradición anglosajona. De acuerdo con la doctrina

49 El capítulo IV del Pacto de Bogotá se refiere al arreglo judicial, en tanto el V corresponde al procedimiento de arbitraje.

50 Artículo 23, Entendimiento Relativo a las Normas y Procedimientos por los que se Rige la Solución de Diferencias en la Organización Mundial del Comercio, 1994.

51 Artículo 92, versión consolidada del Tratado de la Unión Europea, 2012.

52 Notable ejemplo de autoprotección de sus poderes se encuentra en la opinión que sostuvo la Corte Europea de Justicia al conocer uno de los diferentes procedimientos originados de la disputa entre Reino Unido e Irlanda por la Planta MOX, bajo la premisa de la potencial afectación de la autonomía del régimen jurídico europeo. Comisión de la Corte de Justicia v. Irlanda, Sentencia, Caso N ${ }^{\circ}$ C-459/03, 2006, párr. 504. 
del forum non-conveniens, un tribunal o corte competente para conocer de un determinado procedimiento debe declinar el ejercicio de su jurisdicción en favor de otro que se encuentre en una posición más adecuada o ventajosa para conocer del asunto. Sin embargo, creemos que, a pesar de que ha sido sugerido como alternativa, la extrapolación de esta doctrina desde el derecho interno al internacional es un asunto dificultoso. En primer término, no puede ser concebida como un principio de derecho internacional, debido a su prácticamente nula aceptación (e incluso conocimiento) en países con tradiciones jurídicas continentales. Y en segundo lugar, porque presupone el ejercicio de una facultad discrecional por parte de los órganos judiciales internacionales, y en muchos casos los foros competentes para conocer de una controversia específica no se encuentran habilitados para abstenerse de ejercer jurisdicción, debiendo de este modo ejercerla. ${ }^{53}$

\section{b) Procedimientos paralelos}

Constituyen un tipo de procedimientos múltiples en el cual dos o más de ellos penden simultáneamente ante diferentes órganos judiciales. En la determinación de la existencia de procedimientos paralelos, un requisito sine qua non es la existencia de procedimientos efectivamente iniciados ante más de un órgano judicial, por lo que no son posibles de concebir mientras se practica forum shopping. Del mismo modo, es también una condición esencial el que al momento de iniciarse el segundo de los procedimientos, el primero de estos no se encuentre concluido por sentencia definitiva, pues, de lo contrario, se tratará de procedimientos sucesivos. Finalmente, solo estaremos en presencia de genuinos procedimientos paralelos cuando los foros que simultáneamente conocen de una misma disputa existente entre las mismas partes sean efectivamente comparables, al ofrecer soluciones cualitativamente similares.

53 Por ejemplo, el respectivo panel de la OMC conformado para conocer del caso Soft Drinks (Estados Unidos v. México) se enfrentó a la alegación mexicana que sostuvo que debía declinar su jurisdicción en favor del mecanismo contemplado en el capítulo xx del NAFTA, pues entendía que se trataba del foro más apropiado. No obstante, en una decisión preliminar el panel señaló que, al tenor de lo dispuesto en el Entendimiento que Rige la Solución de Disputas de la OMC, no contaba con discreción para decidir si ejercer o no jurisdicción en un caso sometido a su conocimiento, debido a que el sistema de la OMC establece que cada uno de los miembros tendrá el derecho de recurrir ante el mecanismo de arreglo de diferencias por este contemplado. México-Medidas fiscales sobre los refrescos y otras bebidas, informe del grupo especial, WT/DS308/R, 2005, párr. 7.1. 
De ahí que los procedimientos paralelos entre tribunales internacionales han sido de muy escasa ocurrencia, a pesar de que la primera referencia a estos la efectuó hace largas décadas la Corte Permanente en Ciertos intereses germanos en la Silesia Alta Polaca. ${ }^{54} \mathrm{El}$ mayor riesgo involucrado consiste en la posibilidad de que se produzcan decisiones incompatibles en cuanto a su ejecución, o incluso contradictorias. Además, desde un punto de vista práctico, incrementan el costo económico de litigar para las partes, pues estas se ven obligadas a duplicar innecesariamente sus esfuerzos.

El derecho internacional no cuenta con una regulación suficiente de los procedimientos paralelos. Encontramos escasos instrumentos jurídicos que contienen normas aplicables a estas situaciones. Destaca el artículo 2005 del NAFTA: en su virtud, el demandante tiene la posibilidad de escoger el foro para presentar su reclamo (el sistema del GATT o el propio NAFTA), pero, una vez que refiere la disputa ante uno de ellos, este será utilizado con exclusión de cualquier otro. Se trata de una valiosa regla de distribución de competencias, a la que se le denomina electa una via. Un segundo ejemplo lo encontramos en el sistema Europeo. Según el artículo 54 del Estatuto de la Corte Europea de Justicia, en casos que involucren asuntos jurídicos similares, y que se encuentren pendientes ante las dos cortes que establece el sistema — la Corte de Justicia y la Corte General—, cualquiera de las dos puede suspender la respectiva tramitación en tanto la otra no entregue su decisión definitiva. Para Shany, este discrecional ejercicio de mutuo respeto podría servir en un futuro como modelo de regulación internacional de diversas formas de interacción judicial, especialmente en casos donde se constata la existencia de procedimientos paralelos. ${ }^{55}$

No obstante, consideramos que la alternativa más adecuada y práctica consiste en el empleo de la regla lis alibi pendens (litispendencia), mayormente conocida en los países de tradición continental, pero que tiene su símil anglosajón en la doctrina del forum non-conveniens. Compartimos lo señalado por Reinisch, quien ha expresado que, a pesar de las dificultades prácticas que muchas veces existirán para acreditar la triple identidad (de partes, objeto y causa de pedir), hay buenas razones para considerar esta regla como un principio general del derecho, al tenor del artículo 38 del

54 En el referido caso, la Corte Permanente — aunque sin entrar en un análisis detallado- señaló que, para que existiesen múltiples procedimientos (en este caso, paralelos), se requería de la concurrencia de la tradicional triple identidad. Ciertos intereses germanos en la Alta Silesia (Alemania v. Polonia), Jurisdicción, PCIJ Series A Nº, 1924, p. 20.

55 Shany, The competing jurisdiction..., op. cit., p. 223. 
Estatuto de la CIJ. ${ }^{56} \mathrm{La}$ argumentación fluye de una situación lógica: sería incoherente permitir procedimientos paralelos entre las mismas partes, relativos a los mismos hechos y que involucran idénticas consideraciones jurídicas hasta el punto en que uno de los tribunales que conoce del asunto pronuncie su decisión definitiva, y de esta forma, impida que el otro foro cuyo procedimiento aún se encuentra pendiente haga lo mismo, por la aplicación de la cosa juzgada.

En términos prácticos, la discusión sobre la aplicación judicial de la litispendencia se ha producido en escasas oportunidades. Destaca una controversia relativa a la interpretación del artículo 36(1)(b) de la Convención de Viena sobre Relaciones Consulares (derecho a solicitar asistencia consular en caso de detención en país extranjero), en la cual la Corte Interamericana de Derechos Humanos (CIDH) — requerida por México para el pronunciamiento de una opinión consultiva - rechazó una solicitud de los Estados Unidos de abstenerse de emitir dicha opinión debido a la pendencia de procedimientos simultáneos relativos a similares hechos ante la CIJ, aunque entre diferentes partes y de naturaleza distinta (uno consultivo y los otros contenciosos). ${ }^{57}$ En opinión de la CIDH, el "interés general" de los Estados americanos hacia recomendable de todos modos cumplir con su tarea.

De ello se desprende que la principal dificultad para la aplicación de la litispendencia radica en que los tribunales internacionales parecen no estar dispuestos a declinar fácilmente ejercer su jurisdicción en aquellos casos en los cuales su accionar es requerido. Debido a esto, en nuestra opinión, un interesante matiz en tanto persista la insuficiencia normativa consiste en adicionar a la regla de la litispendencia el reconocimiento jurisprudencial del denominado comity o mutuo respeto. Esto implica que los tribunales que operan en distintos subsistemas jurídicos debiesen manifestar un grado de deferencia respecto de la labor que desempeñan sus pares. Apoya el reconocimiento del comity la disputa de la Planta MOX, en

\footnotetext{
56 Reinisch, August, "The use and abuse of res judicata and lis pendens as procedural tools to avoid conflicting dispute settlement outcomes", The Law and Practice of International Courts and Tribunals, 2004, 3, (1), p. 48.

57 La controversia originó el referido procedimiento ante la CIDH (El derecho a la información sobre la asistencia consular en el marco de las garantias del debido proceso legal, Opinión consultiva, 1999); y dos litigios ante la CIJ (La Grand -Alemania v. Estados Unidos—, Mérito, ICJ Reports, 2001; y Caso concerniente a la Convención de Viena sobre Relaciones Consulares - Paraguay v. Estados Unidos_, Medidas provisionales, ICJ Reports, 1998).
} 
la cual el tribunal arbitral constituido bajo las normas del anexo VII de la Convención sobre el Derecho del Mar decidió suspender la tramitación del procedimiento con miras a brindar la oportunidad para que la Corte Europea de Justicia —en un litigio que pendía de forma paralela— se pronunciase en forma previa sobre un punto jurídico específico: si la disputa era o no parte de su jurisdicción exclusiva. ${ }^{58}$ Como la Corte Europea consideró que, de acuerdo con el artículo 292 del Tratado de la Unión Europea, su competencia para pronunciarse sobre el objeto de la disputa era exclusiva, el tribunal arbitral decidió suspender definitivamente la tramitación del asunto, en ejercicio del comity.

En resumen, parece conveniente despejar las dudas y vacilaciones, e incorporar en forma explícita en los estatutos de los nuevos tribunales y cortes una norma conforme a la cual se autoriza a dicho órgano a declinar ejercer jurisdicción si es que, reuniéndose los requisitos de la triple identidad, el asunto ya ha sido presentado ante otro foro. En tanto dicha reforma no se lleve a cabo, el comity podrá ser utilizado como un relevante elemento coadyuvante.

\section{c) Procedimientos sucesivos}

Constituyen la segunda variante que pueden adoptar los procedimientos múltiples, y al mismo tiempo, la menos problemática de ambas al existir una herramienta efectiva y reconocida universalmente para enfrentar sus indiscutidos negativos efectos. Luego de que un tribunal o corte internacional pronuncia una decisión que pone término a la controversia, este pronunciamiento debe entenderse como obligatorio y definitivo para las partes que se sometieron a dicho procedimiento de adjudicación. La hipotética pregunta que surge es si la parte que ha resultado vencida podría re-litigar la misma disputa ante un foro diferente, que estuviere también investido con jurisdicción para conocer del asunto. En un escenario como el descrito, son varias las consecuencias negativas que se aprecian: incerteza jurídica, riesgo de que se pronuncien decisiones contradictorias, merma en el principio de economía procesal, alteración del principio non bis in idem y un evidente menoscabo de los derechos de la parte victoriosa. Por otro lado,

58 Planta MOX (Irlanda v. Reino Unido), Corte Permanente de Arbitraje (tribunal arbitral constituido bajo el anexo VII de la Convención sobre Derecho del Mar), 2003, párr. 28. 
existe un riesgo de que el conflicto permanezca indefinidamente latente, al no existir un incentivo para el cumplimiento de la respectiva sentencia. ${ }^{59}$

La indiscutible vía por la cual estos nocivos efectos son impedidos es mediante la aplicación de la regla de la cosa juzgada. En su virtud, la decisión pronunciada por un tribunal o corte ha de entenderse como definitiva y obligatoria para las partes en cuanto a su cumplimiento. De estas dos características surge un doble efecto: uno positivo, conforme al cual la decisión final emitida por tribunal o corte es obligatoria para las partes que participaron del litigio; y otro negativo, traducido en que la resolución del órgano judicial que pone fin a la disputa tiene la particularidad de ser definitiva, existiendo entonces un impedimento para las partes de iniciar un nuevo proceso, incluso ante otro foro alternativo. ${ }^{60}$

El fundamento tras la consagración de esta regla a nivel internacional descansa en la ponderación de dos tipos de intereses: uno general, de importancia para la comunidad internacional en su conjunto, y otro de carácter específico, vinculado con los intereses de los propios litigantes. ${ }^{61}$ Además, para su aplicación, también se requiere de la constatación de la triple identidad.

A diferencia de la insuficiente normativa destinada a regular la ocurrencia de procedimientos paralelos, gran mayoría de los tribunales y cortes internacionales cuentan en sus estatutos con normas que se refieren a este doble efecto de las sentencias definitivas, del cual se desprende la regla de la cosa juzgada. Ejemplos son los artículos 59 (efecto obligatorio de la sentencia entre las partes) y 60 (la decisión adoptada es final y no susceptible de apelación) del Estatuto de la CIJ, y el artículo 33.1 del Estatuto del TDM (decisión final y obligatoria). Por otro lado, existen importantes argumentos doctrinarios en favor del amplio reconocimiento de

\footnotetext{
59 Shany, The competing jurisdiction..., op. cit., p. 164.

60 Cheng, Bing, General principles of law as applied by international courts and tribunals, Cambridge University Press, Cambridge, 2006, pp. 336-343.

61 Lo anterior ha sido resumido por la CIJ en el caso sobre la Aplicación de la Convención que Sanciona el Genocidio (Bosnia y Herzegovina v. Serbia y Montenegro), en donde consideró: "Dos propósitos, uno general, y otro específico, subyacen al principio de la res iudicata [...]. Primero, la estabilidad de las relaciones jurídicas requiere que los litigios lleguen a su fin [...]. Segundo, está el interés de cada una de las partes de que un asunto que ya ha sido adjudicado a favor de una de ellas no sea discutido nuevamente". Aplicación de la Convención sobre la Prevención y Sanción del Delito de Genocidio (Bosnia y Herzegovina v. Serbia y Montenegro), Mérito, ICJ Reports, 2007, párr. 116.
} 
esta institución de derecho a nivel internacional. Algunos autores consideran que la res iudicata ha pasado a convertirse en una norma de derecho consuetudinario, ${ }^{62}$ mientras que otros la incluyen dentro de los principios generales del derecho, en el sentido de lo estipulado por el artículo 38(1) (c) del Estatuto de la CIJ. ${ }^{63}$

Cualquiera sea la valoración que de ella se efectúe, lo cierto es que tempranamente la aplicación de esta regla fue respaldada jurisprudencialmente por la Corte Permanente de Justicia Internacional, en el caso Sociedad Comercial de Bélgica, en donde sentenció que el reconocimiento de la res iudicata no era otra cosa que la constatación del efecto final y obligatorio de la resolución pronunciada por esta. ${ }^{64} \mathrm{~A}$ partir de ese momento, su estatus y reconocimiento en el interior de la práctica de los tribunales internacionales ha sido afortunadamente incontrovertido.

\section{Conclusiones}

Este trabajo ha pretendido generar una reflexión crítica que puede ser resumida en el siguiente interrogante: ¿constituyen algunas externalidades derivadas de la proliferación elementos perjudiciales o riesgosos para el ejercicio de la función jurisdiccional internacional?

En primer lugar, respecto de las posibilidades de que se produzca una fragmentación del derecho internacional como consecuencia de la dictación de decisiones contradictorias, hemos pretendido descartar que ello obedezca hasta ahora a la existencia de un mayor número de foros internacionales disponibles para resolver controversias. Por el contrario, nuestra conclusión apunta a que el riesgo de fragmentación no se encuentra necesariamente relacionado con la proliferación, ni se trata de un fenómeno

\footnotetext{
62 Dodge, William, "National courts and international arbitration: exhaustion of local remedies and res judicata under chapter eleven of NAFTA", Hasting International and Comparative Law Review, 2000, 23, (1), p. 365.

63 Lauterpacht, Hersch, The development of international law by the International Court of Justice, Cambridge University Press, Cambridge,1958, p. 325. De acuerdo con el artículo 38 del Estatuto de la Corte Internacional de Justicia, al decidir las controversias que son sometidas a su conocimiento, deberá aplicar las convenciones internacionales, la costumbre, las decisiones judiciales y doctrina de los publicistas (como medio auxiliar), y los principios generales del derecho reconocidos por las naciones civilizadas.

64 Societé Commerciale de Belgique (Bélgica v. Grecia), Mérito, PCIj Series A/B No 74, 1939, p. 175.
} 
que represente actualmente una real amenaza para el funcionamiento del sistema. La inexistencia de abundante jurisprudencia contradictoria es uno de los argumentos que sirven para reforzar la idea de que, aun en un contexto de proliferación, el riesgo de fragmentación ha sido más bien una situación teórica que práctica, y que, de acontecer dentro de los márgenes que hasta ahora ha sucedido, representa una tensión natural que debe soportar todo sistema que funciona con prescindencia de la regla del precedente, y que carece de una estructura institucional jerárquica.

En segundo término, similar argumentación puede ser replicada tratándose de los conflictos de jurisdicción que se generan en virtud de la superposición de competencias, aunque con un importante matiz: en este caso, la principal responsabilidad radica en los Estados, pues estos son los encargados de desarrollar ex ante reglas claras de delimitación de competencia, o bien de incluir herramientas jurídicas eficaces para enfrentar aquellos casos en los que se produce un inadecuado ejercicio de forum shopping o en los que pueden generarse múltiples procedimientos, sean estos paralelos o sucesivos.

Tercero, el forum shopping no representa una situación en sí misma conflictiva. Más bien, forma parte del legítimo derecho que le asiste a los sujetos de derecho internacional en cuanto a decidir ante qué foro someter el asunto litigioso, previa ponderación de sus respectivos intereses. Sin embargo, el forum shopping puede tornarse en una práctica inconveniente cuando es llevado a cabo con la única intención de perjudicar los intereses de la contraparte. Dicha situación es de difícil ocurrencia, y aún de más compleja prueba. Hemos también señalado que en la mayoría de los casos no existen contrapesos normativos para palear dicha situación hipotética. De ahí la relevancia del mutuo acuerdo entre las partes para la selección del órgano, o la posible aplicación de la doctrina del forum non-conveniens.

Cuarto, respecto de los múltiples procedimientos, valga también la aclaración de que, considerando el actual desarrollo del derecho internacional, se trata de una situación más bien teórica que práctica, constatándose muy pocos ejemplos en los cuales verdaderos procedimientos paralelos o sucesivos han sido efectivamente iniciados. No obstante, es claro que, de ocurrir, constituiría un efecto negativo para el funcionamiento de la adjudicación internacional, pues daría paso a inconvenientes incertezas y a una peligrosa carencia de predictibilidad.

Particularmente en el caso de los procedimientos paralelos, la alternativa más factible es, en nuestra opinión, la incorporación de una regla de preclusión en cuya virtud, cuando las partes se encuentren facultadas para 
libremente escoger ante qué foro someter la controversia (forum shopping), se establezca que, una vez efectuada la elección, dicho órgano pasará a gozar de jurisdicción exclusiva sobre el respectivo litigio. Si de todos modos el segundo foro fuere requerido, la parte demandada estará facultada para interponer la excepción de litispendencia. En tanto no exista de modo explícito tal regulación, es importante que los tribunales se planteen frente a la labor de sus pares con adecuados niveles de deferencia.

En quinto lugar, donde existe mayor claridad es en la necesaria aplicación de la regla de la res iudicata como herramienta para evitar la reapertura de un caso previamente resuelto (procedimientos sucesivos), protegiendo de esta forma el efecto final y definitivo de las sentencias emanadas de tribunales y cortes, y promoviendo además el esperable cumplimiento de las resoluciones judiciales.

Finalmente, estimamos necesario tomar distancia respecto de posturas alarmistas relativas a las posibles consecuencias negativas de la proliferación de órganos judiciales internacionales, especialmente respecto de la observación que pone el acento en la paulatina pérdida de coherencia del sistema judicial en su conjunto, como consecuencia de la posible fragmentación del derecho substantivo y de la ocurrencia de conflictos de jurisdicción. Es preciso traer a colación que el sistema internacional nunca "ha gozado del tipo de coherencia que puede haber caracterizado a los ordenamientos jurídicos de los Estados", 65 y que, por el contrario, es particularmente conveniente destacar el valor del pluralismo en su calidad de elemento constitutivo del sistema jurídico al que nos referimos.

De este modo, debido a la escasa ocurrencia práctica de los indeseables efectos negativos, han sido los propios años transcurridos desde que se produjera el explosivo aumento en el número de tribunales y cortes el principal argumento para ahuyentar tales aprensiones. Sin perjuicio de lo anterior, no es menos cierto que el sistema de adjudicación internacional debe estar suficientemente preparado para enfrentar situaciones que pudieren ser más conflictivas en el futuro. Aunque ello parece improbable bajo el actual esquema, es importante el desarrollo de prácticas institucionalizadas de diálogo, colaboración y coordinación entre los distintos foros internacionales, y eventualmente entre estos y jurisdicciones nacionales. De esta forma, se fortalecen las posibles interacciones, y se genera un clima

65 Report of the Study Group of the International Law Commission finalized by Martii Koskenniemi, op. cit., para. 493. 
de confianza que resulta vital en un contexto al que le son naturalmente ajenas las relaciones jerárquicas.

\section{Referencias bibliográficas}

\section{Doctrina}

Aznar Gómez, Mariano J., "En torno a la unidad sistémica del derecho internacional", Revista Española de Derecho Internacional, 2007, LIX, (2), pp. 563-594.

Böhm, María Laura, "Informe del x Encuentro del Grupo Latinoamericano de Estudios sobre Derecho Penal Internacional", en Ambos, Kai et al. (Eds.), Análisis de la primera sentencia de la Corte Penal Internacional: el caso Lubanga, Fundación Konrad Adenauer, 2014, pp. 457-473.

Buergenthal, Thomas, "Proliferation of international courts and tribunals: is good or bad?", Leiden Journal of International Law, 2001, 14, (2), pp. 267-275.

Cheng, Bing, General principles of law as applied by international courts and tribunals, Cambridge University Press, Cambridge, 2006.

Dodge, William, "National courts and international arbitration: exhaustion of local remedies and res judicata under chapter eleven of NAFTA", Hasting International and Comparative Law Review, 2000, 23, (1), pp. 357-384.

Dupuy, Pierre-Marie, “The danger of fragmentation or unification of the international legal system and the International Court of Justice", Journal of International Law and Politics, 1999, 31, (4), pp. 791-807.

Fernández Liesa, Carlos R., "La proliferación de tribunales internacionales en el espacio iberoamericano", Revista Electrónica de Derecho Iberoamericana, 2008, 2, (2), pp. 11-22.

Guillaume, Gilbert, "Speech to the General Assembly of the United Nations", 2001, en http://www.icj-cij.org/court/index.php?pr $=82 \&$ $\mathrm{pt}=3 \& \mathrm{p} 1=1 \& \mathrm{p} 2=3 \& \mathrm{p} 3=1 \&$ PHPSESSID $=$

Lauterpacht, Hersch, The development of international law by the International Court of Justice, Cambridge University Press, Cambridge, 1958.

Lauterpacht, Hersch, The function of law in the international community (introduction Martii Koskenniemi), Oxford University Press, Oxford, 2011.

Reinisch, August, "The use and abuse of res judicata and lis pendens as procedural tools to avoid conflicting dispute settlement outcomes", 
The Law and Practice of International Courts and Tribunals, 2004, 3, (1), pp. 37-77.

Remiro Brotóns, Antonio et al., Derecho internacional, Tirant lo Blanch, Valencia, 2007.

Rodiles, Alejandro, "La fragmentación del derecho internacional: ¿riesgo u oportunidad para México?", Anuario Mexicano de Derecho Internacional, 2009, Ix, pp. 373-413.

Romano, Cesare, "The proliferation of international judicial bodies: the pieces of the puzzle", Journal of International Law and Politics, 1999, 31, (4), pp. 709-751.

Schwebel, Stephen M., "Address to the General Assembly of the United Nations", 1998, en http:/ / www.icj-cij.org/presscom/files/7/3007.pdf

Shany, Yuval, The competing jurisdiction of international courts and tribunals, Oxford University Press, Oxford, 2003.

Study Group of the International Law Commission, "Fragmentation of international law: difficulties arising from the diversification and expansion of international law", Report of the Study Group of the International Law Commission finalized by Martii Koskenniemi, A/CN.4/L.682, 2006.

\section{Jurisprudencia citada}

Actividades militares y paramilitares en y en contra de Nicaragua (Nicaragua v. Estados Unidos), Mérito, ICJ Reports, 1986.

Aplicación de la Convención sobre la Prevención y Sanción del Delito de Genocidio

(Bosnia y Herzegovina v. Serbia y Montenegro), Mérito, ICJ Reports, 2007.

Aplicación de la Convención sobre la Prevención y Sanción del Delito de Genocidio (Croacia v. Serbia), Mérito, ICJ Reports, 2015.

Caso concerniente a la Convención de Viena sobre Relaciones Consulares (Paraguay

v. Estados Unidos), Medidas provisionales, ICJ Reports, 1998.

CIDH, El derecho a la información sobre la asistencia consular en el marco de las garantías del debido proceso legal, Opinión consultiva, 1999.

Ciertos intereses germanos en la Alta Silesia (Alemania v. Polonia), Jurisdicción, PCIJ Series A No 6, 1924.

CMS Gas Transmission Company v. Argentina, Icsid Case No ARB/01/8, 2005. Comisión de la Corte de Justicia v. Irlanda, Sentencia, Caso No C-459/03, 2006. Delimitación de la frontera marítima en el Golfo de Maine (Canadá v. Estados Unidos), Mérito, ICJ Reports, 1984. 
Delimitación maritima en el área entre Groenlandia y Jan Mayen (Dinamarca v. Noruega), ICJ Reports, 1993.

Delimitación marítima en el Mar Negro (Rumania v. Ucrania), Mérito, ICJ Reports, 2009.

Delimitación maritima y cuestiones territoriales (Qatar v. Bahréin), Mérito, ICJ Reports, 2001.

Fosfatos en Marruecos (Italia v. Francia), Objeciones preliminares, PCIJ Series $\mathrm{A} / \mathrm{B} \mathrm{N}^{\circ} 74,1938$.

La Grand (Alemania v. Estados Unidos), Mérito, ICJ Reports, 2001.

LG\&E Energy Corp. et al. v. Argentina, Decision on liability, Icsid Case $\mathrm{N}^{\circ} \mathrm{ARB} / 02 / 1,2007$.

Loizidou v. Turkey, Preliminary objections, ECHR Case No 15318/89, 1995.

México-Medidas fiscales sobre los refrescos y otras bebidas, informe del Grupo

Especial, W'T/DS308/R, 2005.

Pesquerías (Reino Unido v. Islandia), Mérito, ICJ Reports, 1974.

Pesquerías (Reino Unido v. Noruega), Mérito, ICJ Reports, 1951.

Planta MOX (Irlanda v. Reino Unido), Corte Permanente de Arbitraje (Tri-

bunal Arbitral constituido bajo el anexo VII de la Convención sobre

Derecho del Mar), 2003.

Plataforma continental (Libia v. Malta), Mérito, ICJ Reports, 1985.

Plataforma continental (Tunes v. Libia), Mérito, ICJ Reports, 1982.

Plataforma continental del Mar del Norte (República Federal de Alemania v.

Dinamarca/Países Bajos), Mérito, ICJ Reports, 1969.

Prosecutor v. Tadic, ICTY, Cámara de Apelaciones, Decisión sobre la moción de apelación interlocutoria sobre jurisdicción presentada por la defensa, Caso No IT-94-1, 1995.

Prosecutor v. Tadic, ICTY, Cámara de Apelaciones, Sentencia, Caso No IT-94-A-1, 1999.

Prosecutor $v$. Thomas Lubanga Dyilo, ICC, Sala de Primera Instancia, Decisión de acuerdo con el artículo 74 del Estatuto, Caso ICC-01/04-01/06, 2012.

Reservas a la Convención para la Prevención y Sanción del Delito de Genocidio, Opinión consultiva, ICJ Reports, 1951.

Societé Commerciale de Belgique (Bélgica v. Grecia), Mérito, PCIj Series A/B $\mathrm{N}^{\mathrm{o}} 74,1939$. 
